\title{
Conceptual design method and creativity in textile design
}

\begin{abstract}
In textile sector intuitive non-engineering methods and skill based designer oriented design processes are regarded as appropriate for textile manufacturing. However, design presented by the use of Prescriptive design models concludes to be more direct and rapid when compared to the Descriptive design models. For these reasons, systematic design techniques prove to be more scientific and easy to manipulate when compared to classical intuitive design techniques. Since textile, as an industrial product in essence, has its own design paradigms and scientific background, it has to define its own methodology in an attempt to form a scheduled, programmed and repeatable design process.

The primary objective of this research is to provide support to the textile designer during early stages of the design process by using Conceptual Design steps, which can be used as a creative analysis process in textile design problems providing a high level of creativity. The Pahl and Beitz model is employed to investigate critical and complicated design problems of three design projects, each conducted by different student, solving different design requests from different fields of textile sector and thus, each fulfilling different transformation functions and design solutions. The resulting collections are presented and the steps of process are discussed in the Results \& Discussion part.
\end{abstract}

Keywords: textile design, systematic design approach, conceptual design, pahl \& beitz model, creativity
Volume 3 Issue I - 2017

Banu Hatice Gürcüm
Department of Textile Design, Gazi University, Turkey

Correspondence: Banu Hatice Gürcüm, Associate Professor of Textile Design Department, Gazi University, Ankara,Turkey, Email banugurcum@gmail.com

Received: August 25, 2017 | Published: October 06, 2017

\section{Introduction}

Design has long been regarded as an intentional problem solving action and has become the focal point of events prepared for professional activities almost in every sector. In design practice, though a methodological approach to design problems is usually not formalized and hardly internalized, a precise design problem is generally observed. Assoreira Almendra ${ }^{1}$ concludes that the lack of methodological approach in design "results in irregular final solutions in terms of overall quality, productivity, as well as strategic adequacy to markets and firm's aims". Despite the deficiency of a clearly described design method, a designer is often urged to start investigating about the concept and context of the problem together. However, the usual design approaches of intuition, visualizing and feeling ones way round a solution do not help when a designer is unable to fully envisage how the solution will behave Love. ${ }^{2}$ In case he is intuitively successful and keen to transform the ill focused multipossibility initial stage into a well-defined, fully detailed, final design stage, he presents "the solution" satisfying the contend of the problem.

The study of design processes is one field of Design Research that for the past four decades consistently has produced more information and reflection. Design is accepted as problem solving activity that can be considered in the light of cognitive science. This is best recognized in the definition of Christiaans \& Restrepo: ${ }^{3}$ “. ... [design is] an information processing activity... being the problem solvers [designers] assumed [design] as information processing systems." However, Christiaans \& Restrepo ${ }^{3}$ also complains about the deficiency of information about the problem: because of the very nature of design problems, there is very often very little information about the problem, even less information about the goal (solution) and absolutely no information about the transformation function. This means that design problems require a lot of structuring.

Problem structuring and solution structuring have been studied intensely in the past twenty years in various areas of Design Knowledge. It is the case of design engineering where some of the models produced propose that first engineers make the analysis of the problem and in sequence they synthesize a solution Pahl \& Beitz; ${ }^{4}$ Roozenburg \& Eekels. ${ }^{5}$ Unfortunately textile sector is a design domain where Design Research plays a relatively small role in the everyday routine, even though design is the essential key to the products that are manufactured. The paucity of research in textile sector is best explained by the presence of understanding that intuitive non-engineering methods and skill-based designer oriented design processes are appropriate for textile manufacturing. For many years, textile and apparel sector focused only on answering the orders received from the market and fulfilling the trends opposed by others in a commissionaire approach. Though textiles have many wider scientific implications and are regarded as scientific assets for many other sectors from automotive industry to medical applications, they have long been regarded as 'beautiful aesthetic fabrics'. Studd ${ }^{6}$ mentions that research tends to assume textiles to be either productrelated or about surface patterns, and so akin to the graphic. Moxey ${ }^{7}$ discusses about the lack of rules or conventions dictating how couture products should be developed and presented.

However, textile designers are getting more and more curious about the Design Research and Design Knowledge both in aesthetic and technical fields of textile. Non-intuitive methods and design strategies best suiting for textile design have been studied more nowadays. Many creative design strategies have been developed in 
textile design field and various design tools have been developed for designers to work with design situations. It is known that all the design solutions put forth by the designer during the conceptual stage effect all the processes and the decisions inside the design period. Thus, this paper deals with Conceptual Design Method and the phases of iterative creativity in aesthetic textile product design. The aim of this research is to explain the application of Conceptual Design Method as a creative analysis tool available for textile design problems and to showcase the level of creativity exposed during Conceptual Design process in textile design.

\section{Conceptual design}

Some researchers, mostly in the engineering domain conclude that creative design presented by the use of Prescriptive Design Models concludes to be more direct and rapid when compared to the Descriptive Design Models. This is because systematic design techniques prove to be repeatable, logical, scientific and easy to manipulate when compared to classical designer based intuitive design techniques. Conceptual Design method, which is one of the most applied models to solve complex engineering design problems, has been introduced as the beginning phase of the well-known Prescriptive Design Process in 1984, later became as one of the most frequently used design methods. It is the most detailed and widely referred model of design which was developed by Pahl \& Beitz. ${ }^{8}$ It is our belief that by the help of Conceptual Design method used as decision-making process and employing the previous solutions of the similar problems, the structure of the design problem becomes lucid and thus, the most difficult textile design problems can be solved.

Conceptual Design aims to identify the basic principles and outline of a design solution (or concept) Kannengiesser \& Gero. ${ }^{9}$ The Systematic Approach in Pahl and Beitz model describes engineering design as a sequence of four phases: Clarification of task, Conceptual Design, Embodiment Design, and Detail Design Pahl \& Beitz ${ }^{4}$ (Figure 1). Task Clarification is concerned with collecting, formulating and documenting the requirements of the product to be designed Kannengiesser \& Gero. ${ }^{9}$ The activities a designer should conduct in Task Clarification phase are listed as defining basic market demands; defining attractiveness demands of the market segment; documenting customer-specific technical performance requirements; refining and extending the requirements using the checklist and scenario planning and determining demands and wishes. The input of this phase is the task info and the output of this stage is the specifications list. Conceptual Design phase begins with identification of the essential problem and deals solely with concept. The activities inside Conceptual Design phase is abstracting to identify the essential problems; establishing function structures: overall function -sub functions; searching for working principles that fulfill the subfunctions; combining working principles into working structures; selecting suitable combinations; firming up into principle solution variants and evaluating variants against technical and economic criteria. The input of this phase is the specifications list and the output of this stage is the concept. Embodiment Design then elaborates the design into a layout that satisfies various technical and economic criteria. Detail Design finalizes the design and prepares production documents. Each of the four phases comprises a sequence of activities that may be executed iteratively. After every phase a 'decision-making step' is performed to assess the results of the phase and decide whether the subsequent phase can be started or whether the phase needs to reiterate Kannengiesser \& Gero. ${ }^{9}$
As a basic psychological process, concept design is often divided into three phases, which are described by Osborn ${ }^{10}$ as the creative problem solving process comprising: fact finding (problem definition and preparation), idea finding (thinking up ideas and leads) and solution finding (evaluation and adoption). Similarly, Wodehouse \& Ion ${ }^{11}$ argues that Prescriptive processes tend to follow a basic structure of analysis-synthesis-evaluation where analysis addresses all the design requirements for a problem, synthesis addresses solutions for each performance specification and evaluation addresses the accuracy with which these meet the requirements. If we are to equalize the two approaches for the best understanding of the phase, fact finding usually gathers around the analysis stage or the clarification of the task phase. Idea generation [finding], on the other hand, gathers around the conceptual design phase during identifying essential problems and establishing function structures of a design problem. Solution finding stage is determined as the technical and economical evaluation phase at the end of conceptual design.

\section{Creativity in conceptual design of a textile product}

Creativity is often regarded as the generation of imaginative new ideas Newell \& Shaw, ${ }^{12}$ involving a radical newness innovation or solution to a problem, and a radical reformulation of problems. Imagination, which involves the generation of ideas not previously available as well as the generation of different ways of seeing events, is important to achieve creative actions Dt Ogilvie. ${ }^{13}$ When talking about idea generation, Goldschmidt ${ }^{14}$ proposes creativity as an important issue to attend to. Creativity is the sudden insight which comes to a designer as significant during problem solving. However, Dorst \& Cross $^{15}$ explain this sudden insight as the retrospective moment "that the designer $(\ldots)$ is able to identify a point during the design process at which the key concept began to emerge". They also conclude that retrospective accounts of creative events in design made by the designers themselves may not be wholly reliable Dorst \& Cross. ${ }^{15}$ Since creativity cannot be induced into an empty content; it should be furnished with knowledge derived from design practice, field expertise or ethnographic measures and mostly from insights gained through requirement analysis and critical observations. An intention to create new forms can be a starting point for any designer who will also use elements derived from the social and natural environment to achieve product variations Colchester. ${ }^{16}$ This activity is often focused upon the achievement of some objective that manifests itself in the form of a problem. A number of researchers argue that designers solve specific problems that are either presented to them or defined by themselves Cooke, ${ }^{17}$ Goldschmidt. ${ }^{18}$

Although solution finding for solving a problem force designers to plan the steps of design process by preparing briefs about the task, anticipating customer and market requirements, producing design samples, Bruce \& Cooke $^{19}$ confirm that designers spend a fraction of the total project time developing design ideas. Developing design ideas is the way creative designers manage to draw inspiration and produce novel solutions for the design solution. It is however, true that inspiration drawing in intuitive design processes happens incidentally and design creativity needs a search process in the form of a less formal investigation. Designers appear actively to seek periods where the serendipitous discovery of elements Tucker, ${ }^{20}$ the incubation of ideas, and the resolution of problem impasses may occur. However, in Conceptual Design function analysis urges designer's mind to be more creative and open, therefore he can innovatively think and respond to the unusual solutions for the concepts with respect to functional 
requirements. Conceptual Design educates designer's imagination to generate obscure solutions or to design product concepts which satisfy desired functions unconventionally. This situation is because of the wider range provided by the function analysis phase of Conceptual Design.

Finding the transformation function or primarily function analysis is the key to success in Conceptual Design. Though researchers have attributed different meanings to the term "function", many of them agree in classifying such notion into two categories (Deng, 2002 cited in Giampa, Muzzupappa\& Rizzuti, 2004:1) such as purpose function and action function. Purpose function is explained as the description of the designer's intention or the purpose of a design. It is thus abstract and subjective, whereas action function is explained as an abstraction of how one wishes the product to function and at the same time it individualizes the more convenient working Giampa et al. ${ }^{21}$ In textile design problems we suggest the study of functions of the textile as a whole not as purpose function and action function separately, unless it is high-tech textile based engineering design problem.

So, creativity is a 'highly complex construct' Mumford \& Gustafson; ${ }^{22}$ Perkins. ${ }^{23}$ As a response to this complexity, a multidisciplinary community of creativity theorists has emerged in an effort to understand its peculiarities. This has resulted in theories that attempt to describe the underlying cognitive, social, and cultural variables that regulate the generation of creative products. A theory that encompasses textile design process must address this multiplicity and large number of variables. Thus, the multidisciplinary nature of the textile designer's role means that the textile designer should be equipped as part artist, part technologist, and part social scientist to meet the ever-increasing demands for innovation, variety, and consumer satisfaction. For example an appropriate response repertoire for a printed textile designer would mean awareness of both historical and current developments in printing technology, wet processes, dyestuffs, fiber properties, fabric structures, mixed media, painting techniques, design styling, and design repeat layouts if chances of creative achievement are to improve Joyce. ${ }^{24}$ This greater repertoire urges textile designer to derive information and inspiration from an ocean of concepts from magazines, trade fairs, exhibitions, museums, galleries, art movements, theatres, cinema, published materials, books, architecture, television, to 'the street'. Designers in textile sector can be inspired by history, philosophy, myths, art, music, motion pictures, and etc.

Roy ${ }^{25}$ explains the working methods of a designer for creativity as: Inventors and designers tend to adopt a 'solution-focused' strategy with an initial idea or 'primary generator' created early on which guides the product development process. This primary generator is often derived from the accumulated technical or design 'repertoire' of the individual, comprising knowledge of particular production processes or materials, admired or favorite products, and so on. This repertoire of knowledge and experience is far more useful than the numerous formal techniques that have been developed to foster creativity. Individual inventors and designers typically employ a mix of $2 \mathrm{D}$ sketching and $3 \mathrm{D}$ physical modeling to conceive and then develop their inventions and designs. The mix will depend partly on the nature of the problem to be solved and partly upon the preferred working method of the individual.

While doing inspiration drawing designers use sketchbooks, visual diaries, journals, and notebooks, which contain elements such as postcards, fliers, photocopies, photographs, sketches, painted work, fabric indicators, yam wrappings, trimmings, and written notes (records of ideas and thoughts) to overcome problems with memory recall. These storage devices can act as both an aide memoire and a source of inspiration in which eclectic borrowings of everything and anything reflect 'long periods of research' McDowell. ${ }^{26}$ These are vital for generating successful concepts from which the final collection will be developed. Conceptual design method may also enjoy the use of simple aesthetic tools together with engineering tools like CAD, simulation software as a source of inspiration or memory.

Observational drawing and sketching (as external representations of internal concepts) are an important part of the training of both fashion and textile designers Conran. ${ }^{27}$ Fashion sketches are used primarily to represent the size and shape of silhouettes (which describe the outline of a garment) and in describing the relationship of design elements in 2D form. A sketch can quickly and efficiently describe design elements such as proportion, balance, and rhythm Frings. ${ }^{28}$ Both fashion and textile designers produce observational drawings and sketches that act as the basis for motifs and pattern elements. Fashion and textile designers often present ideas in the form of montages composed of visual material (photographs, magazines clippings, color chips, fabric indicators, trims, and bundles of yam) collected from sensory wanderings Bruce \& Cooper. ${ }^{29}$ These represent composites of distinct visual elements that reinforce the direction the product solution should follow such as Mood, Story, Concept or Color boards. These boards are used to communicate trends, end-user lifestyles, aesthetic considerations, and functional aspects of future solutions. They support and clarify the concept being represented: a form of multiple representations that is 'essential in indeterministic processes such as design problem-solving' Goldschmidt. ${ }^{18}$

Either 2D sketching or 3D Physical modeling, it is important that elements of information and materials collected from these periods of research are recorded and arranged in a form that assists the development of ideas and prosper creativity. Moreover, when Conceptual Design method is applied to textile, the search for stimuli should be planned systematically through use of design methodology steps and deeper analysis for each of the solution alternatives presented in Function Analysis Table should be done and each combination should be studied logically.

\section{Materials and methods}

The methodology for this study included qualitative research collected from primary and secondary resources regarding new textile product development processes. The sample included the textile and apparel collections constructed for and in local textile companies in Turkey. The study was conducted in $2017 \mathrm{AW}$ season to question the possibility of employing conceptual design process steps explained in Figure 1 for the construction of new design projects of various textile fields.

The participants of this research were three design teams making 3 different design projects according to the Conceptual Design algorithm prepared by Pahl \& Beitz (Figure 1). Each teams consisted of two persons; a novice designer, who directed the design project herself and an experienced senior designer who limited the assets of the conceptual design method. The design problem was given to each team and after literature review each team presented its project to determine function structures overall function and sub-functions. Using the brainstorming technique together with all the participants, the teams decided to use the same overall function. For each project, description of the task was made and the sub-functions of the product $(\mathrm{Fi})$ and the solution 
alternatives set (Ri) were determined by the teams independently and presented below (Tables 1-3).

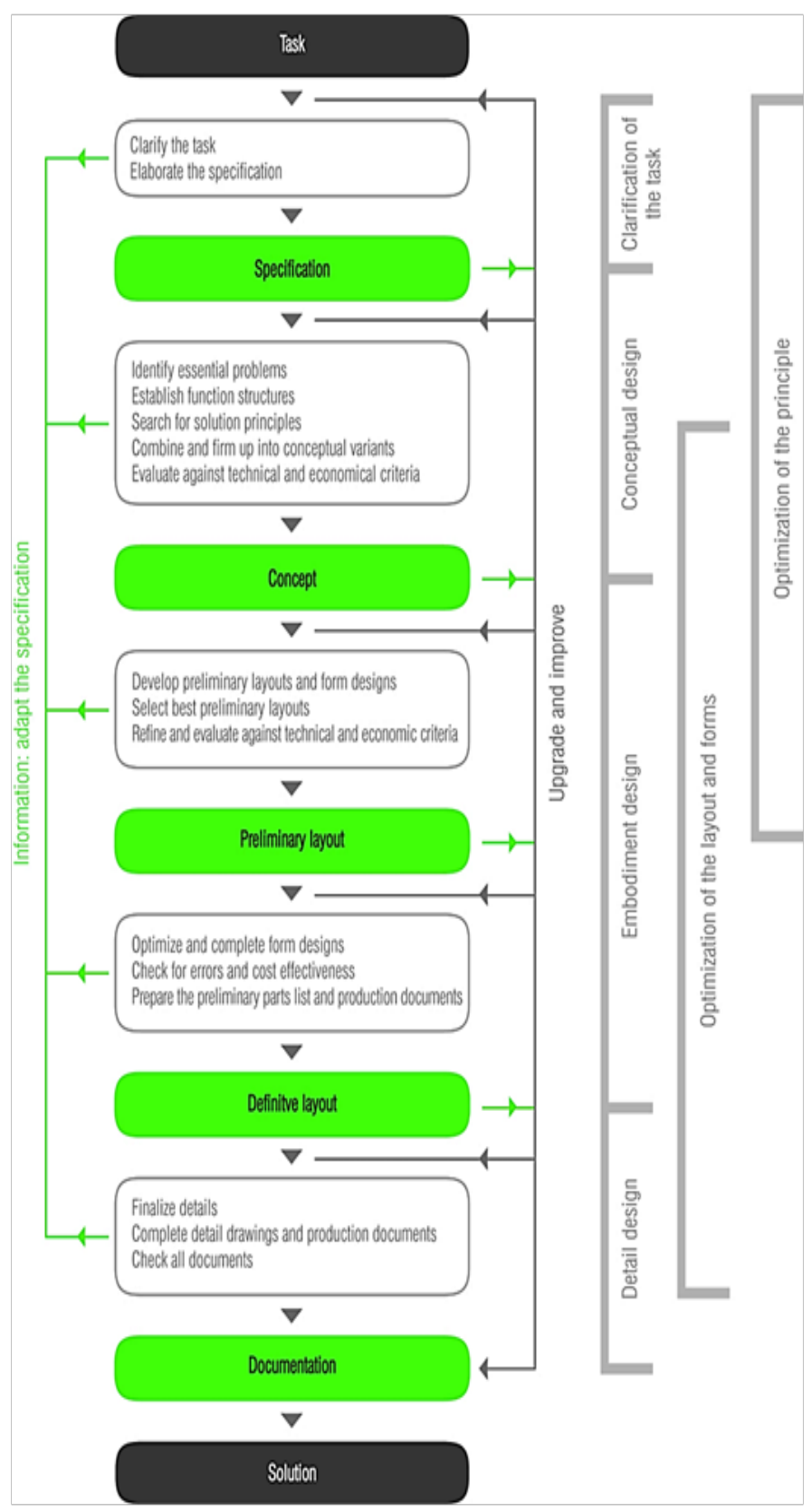

Figure I Design process Pahl \& Beitz, ${ }^{4}$ cited in Assoreira Almendra. ${ }^{\prime}$

The Design problems for the teams were Project 1 double sized print bed linen-duvet collection; Project 2 print scarf collection for Project I: Print duvet collection for double size (Table I)

Table I Function analysis for Project I women; Project 3 print fabric collection for women's apparel. The expected features of the collections were expressed to be focusing upon aesthetic and financial concerns for marketability and technical concern for manufacturability. As seen from the function tables below, the combinations of sub function alternatives were evaluated and decided upon the optimal solution of the design problem. The researchers' industry backgrounds, experiences and expertise areas provided the opportunity to dialogue with industry personnel, as well as identify the key issues in design, development, materials, marketing, and technology required in the project. Senior designer's expertise being in design management, with more than 25years in the textile industry with experiences in hosiery, apparel, couture and home furnishings industries, with the most recent industry position as Apparel Packing and Quality Control Director for one of the Turkeys' largest textile companies. The second researchers in each team had the expertise in textile and design and were being educated at the level of graduate.

Decisions on which fabric to utilize in garment design can be decided by aesthetic criteria (e.g. color, texture, lustre, pattern, handle), functional criteria (e.g. sewability. insulation, dissipation, rub-fastness), and commercial criteria (e.g. right time, right price, right quality) Carr \& Pomeroy. ${ }^{30}$ Likewise, decision on the solution alternatives of Conceptual Design can be decided by aesthetic criteria, functional criteria, commercial criteria and financial criteria. These requirements can be defined quantitatively, for example, by achieving color-fastness, light-fastness, and seam-strength standards. However, much of fashion and textile design is regulated by attributes that escape these kinds of measurement. These include a desire for symmetry (or asymmetry) and the communication of personality statement and social status. In some couture problems designers who are engaged within what McRobbie calls 'ideas fashion' McRobbie ${ }^{31}$ tend to give aesthetic problems priority over performance and price. This situation is abstract and subjective since the overall purpose function differs in every design problem, but may well be overcome through experience and knowhow of the textile sector. When the number of combination possibilities of (Fi over Ri) are determined, it is well recognized that Conceptual Design will enhance creativity of a designer in the same problem by only changing the combinations of the function solution thus switching the satisfaction degree of design problem function namely the textile or apparel customer.

\section{Results and discussion}

Cross $^{32}$ argues Prescriptive processes tend to follow a basic structure of analysis, synthesis and evaluation sequence. Conceptual Design method as a prescriptive process follows the same sequence too. The process began with the search for the Transformation function, namely function analysis and the solution alternatives for each sub function are summarized in tables below (Tables 1-3).

\begin{tabular}{|c|c|c|c|c|c|}
\hline Solution Alternatives & \multirow{2}{*}{$\mathbf{I}$} & \multirow{2}{*}{2} & \multirow{2}{*}{3} & \multirow{2}{*}{4} & \multirow{2}{*}{5} \\
\hline Sub Functions & & & & & \\
\hline FI:Material-structure & $\% 100$ Co-Ranforce & $\% 100$ Co-Poplin & $\% 100$ viscose-satin & \%।00 Bamboo-Ranforce & $\% 100$ Co-sateen \\
\hline F2:Print technique & Hand print & Flat screen print & Rotary screen print & Transfer print & Digital print \\
\hline
\end{tabular}


Table Continued.

\begin{tabular}{|c|c|c|c|c|c|}
\hline Solution Alternatives & \multirow{2}{*}{ I } & \multirow{2}{*}{2} & \multirow{2}{*}{3} & \multirow{2}{*}{4} & \multirow{2}{*}{5} \\
\hline Sub Functions & & & & & \\
\hline F3:Design style & Constructivism & Cubism & Surrealism & Fauvism & Art Nouveau \\
\hline F4:Motif form & Natural & Stylized & Symbolic & & \\
\hline F5:Motif style & Vegetal motifs & Masks and human & Lines and angles & Animals & \\
\hline F6: Color & Color harmonies & Popular colors & Trend colors & Monochrome color & \\
\hline
\end{tabular}

Project 2: Print scarf collection for women (Table 2)

Table 2 Function analysis for Project 2

\begin{tabular}{|c|c|c|c|c|c|}
\hline Solution alternatives & \multirow{2}{*}{ I } & \multirow{2}{*}{2} & \multirow{2}{*}{3} & \multirow{2}{*}{4} & \multirow{2}{*}{5} \\
\hline Sub functions & & & & & \\
\hline FI:Material-structure & \% I 00 silk-Satin & $\% 100$ Pes-Satin & Pes-Co mix-Sateen & Pes-Vis mix-Satin & $\% 100$ Co-Satin \\
\hline F2:Print technique & Hand print & Flat screen print & Rotary screen print & Digital print & Transfer print \\
\hline F3:Design style & Cubism & Futurism & Surrealism & Fauvism & Pointillism \\
\hline F4:Motif form & Natural & Stylized & Symbolic & & \\
\hline F5:Motif style & Arabesque motifs & Fractal motifs & Caleidescope motifs & Mandala motifs & $\begin{array}{l}\text { Geometric and } \\
\text { ribbon motifs }\end{array}$ \\
\hline F6: Color & Color harmonies & Popular colors & Trend colors & & \\
\hline
\end{tabular}

Project 3: Print fabric collection for women dress (Table 3)

Table 3 Function analysis for Project 3

\begin{tabular}{|c|c|c|c|c|c|}
\hline Solution alternatives & \multirow{2}{*}{$\mathbf{I}$} & \multirow{2}{*}{2} & \multirow{2}{*}{3} & \multirow{2}{*}{4} & \multirow{2}{*}{5} \\
\hline Sub functions & & & & & \\
\hline FI:Material-structure & $\%$ I 00 silk-Satin & $\% 100$ Pes-Satin & Pes-Co mix-Sateen & Pes-Vis mix-Satin & $\% 100$ Co-Satin \\
\hline F2:Print technique & Hand print & Flat screen print & Rotary screen print & Digital print & Transfer print \\
\hline F3:Design style & Art Deco & Futurism & Surrealism & Fauvism & Pointillism \\
\hline F4:Motif form & Natural & Stylized & Symbolic & & \\
\hline F5:Motif style & Vegetal motifs & Masks and human & Lines and angles & Animals & \\
\hline F6: Color & Color harmonies & Popular colors & Trend colors & & \\
\hline
\end{tabular}

Analysis: The analysis phase is the phase which addresses all the design requirements for a problem. Defining the task clearly, basic market needs and attractiveness demands of the market segment are the basis of understanding the customer appeal. Each design team prepared customer-specific technical performance requirements for the textile product collections and made inquiries about their project. This step eased the refinement of requirements of the collection and the solution sets. It is known by the researchers that if analysis of the problem is not well done, detail design and manufacture cannot fix the results of a poor conceptual design analysis. Though there are many techniques and tools for generating creative ideas, brainstorming is undoubtedly one of the most popular creative techniques used by organizations Faure. ${ }^{33}$ After the design problem was given teams focused on deriving useful information about the concepts. They sought information and inspiration from art, history, philosophy, myths, music, motion pictures magazines, trade fairs, exhibitions, museums, galleries, theatres, cinema, published materials, books, architecture, television, to 'the street'. They made literature reviews and many observations, which were presented to other teams in many design sessions. After a two month time for searching, presenting, discussing about the specs of their project, the teams made a brainstorming session to determine function structures overall function and sub-func- tions. Using the brainstorming technique together with all the participants, the teams decided to describe sub-functions of the product (Fi) as F1: Material-structure; F2: Print technique; F3: Design style; F4: Motif form; F5: Motif style; F6: Color.

Later each teams decided independently on the solution alternatives set (Ri) were determined by the teams independently and presented above (Tables 1-3). Solution alternatives were presented by each team with samples, research files and design outcomes were also discussed for each of it. As seen from the function tables above, the combinations of sub function alternatives were evaluated and decided upon the optimal solution of the design problem. The researchers' industry backgrounds, experiences and expertise areas added much in deciding the creative, innovative, unique designer made solutions for textile products.

Synthesis: The synthesis phase is the phase which addresses solutions for each performance specification. When dealing with the design problem, designers often forget to consider the solution through the transformation function and all its agents. Normally, a concept at this stage is evaluated and selected on the basis of the desired functional requirements only, neglecting the impact of concept selection on subsequent life-cycle phases like manufacturing, use, maintenance, and 
disposal, as well as on the user satisfaction of the product. Also important to the adoption of this stage as a central one was the fact that it is the phase that is most studied, under different perspectives and about several issues and that provided us with richness of information that was important to the development of this approach. In this way, it is possible to compare results and also contribute for a better knowledge of this complex and very dynamic stage of design processes Assoreira Almendra. ${ }^{1}$

After selection and prioritization of each project (Project 1 double sized print bed linen-duvet collection; Project 2 print scarf collection for women; Project 3 print fabric collection for women's apparel), researchers reported that the design process may begin with consumer or sector observation to define technical and form specifications. Designers also need to find reasonable inspiration sources and have to develop interesting stories deriving from concepts. The functions and design principles of each project and the solution alternatives for each function are presented. For each of the design problem function structures overall function-subfunctions are established. The teams have searched for working principles that fulfill the subfunctions (Tables 1-3).

Concept design is often divided into three phases, which are described by Osborn ${ }^{10}$ as fact finding (problem definition and preparation), idea finding (thinking up ideas and leads) and solution finding (evaluation and adoption). Here fact finding was used as inspiration and idea finding was used as theme and solution finding as concept generating. Below tables (Tables 4-6) detail the concept generating phases of each design team. The inspiration sources resulted in Art Movements after rigorous study. They are explained as Fact finding in Tables 4-6. The teams also constructed sketches, CAD designs, and story, mood and color boards about their projects around a theme, which they presented. The themes they chose should coincided with the combo of alternatives they have made in function analysis stage. They rationalized their choice of themes. These are explained a İdea Finding in Tables 4-6.

\section{Project I: Print duvet collection for double size (Table 4)}

Table 4 Concept generating phases for Project I

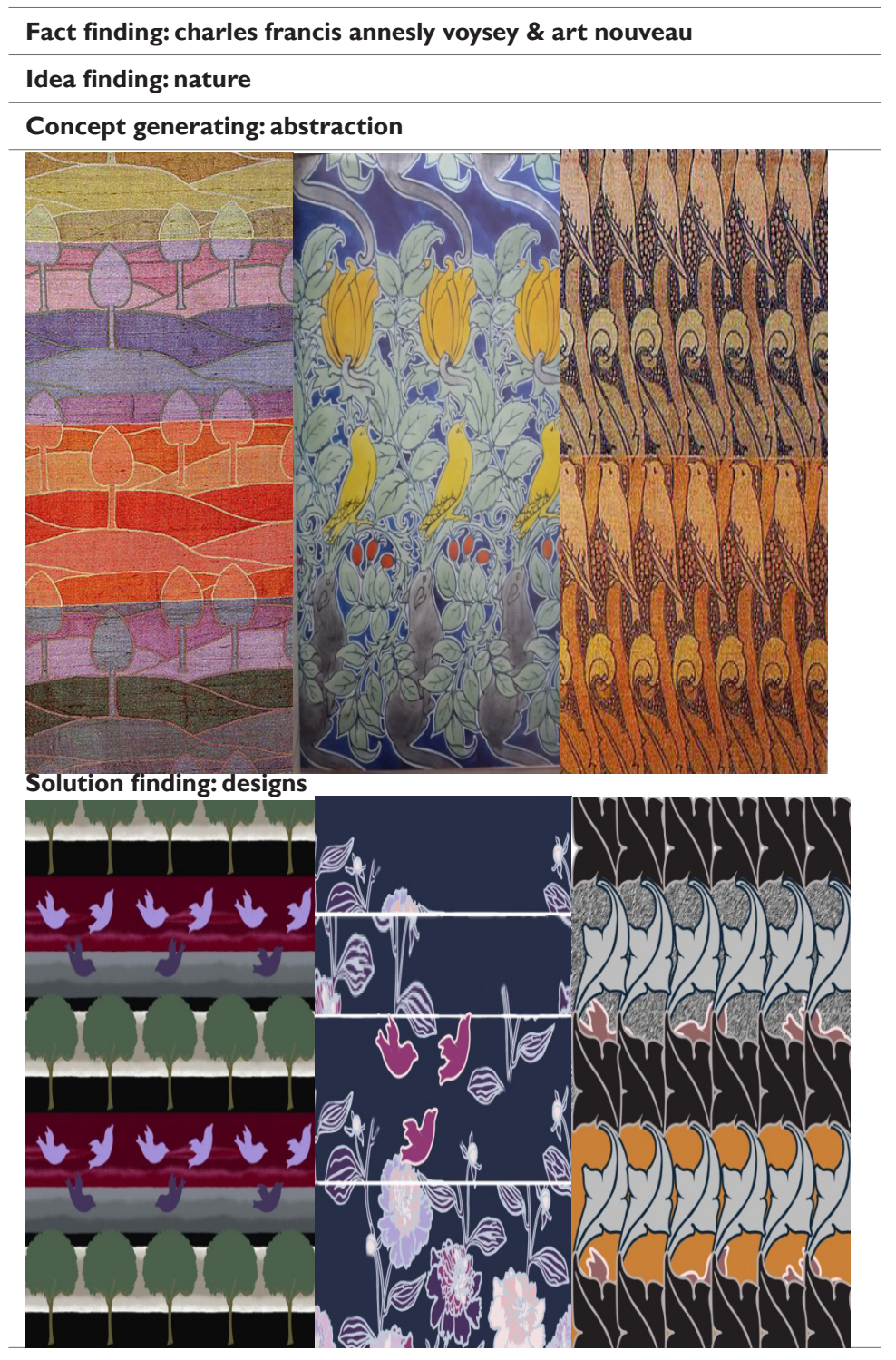


Fact finding: Team 1 derived inspiration from Charles Francis Annesly Voysey, reknown architect and his Art Nouveau designs. Studying Voysey's biography and designs, the team concluded about the subfunctions of the design F1 (Material and structure) as \%100 viscose and satin; F2 (Print technique) as digital print; F3 (Design style) as Art Nouveau; F4 (Motif form) as natural; F5 (Motif style) as animals and

\section{Project 2: Print scarf collection for women (Table 5)}

Table 5 Concept generating phases for Project 2
F6 (Color) as using color harmonies.

Idea finding: Team 1 decided to derive ideas from nature and use pastoral scenes.

Concept generating: Team1 generated their concepts by abstracting Voysey's previous designs.

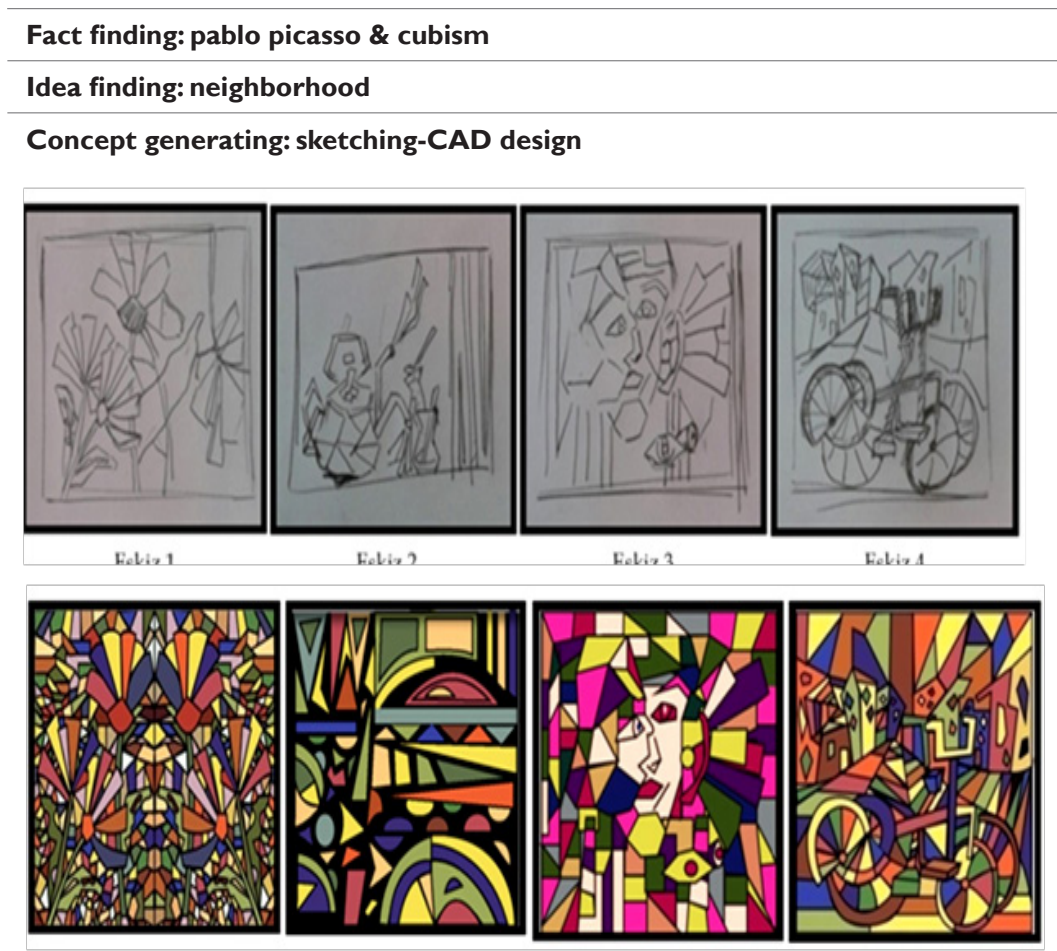

Solution finding: designs

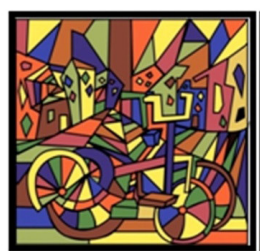

Ön Tasarm 1

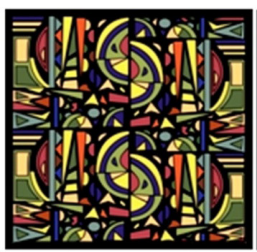

Ön Tasarm 5

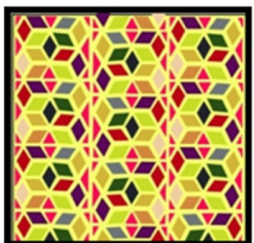

Ön Tasarm 9

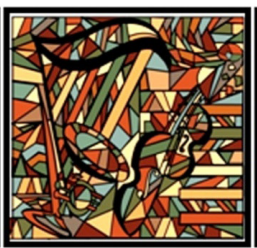

Ön Tasarm 2

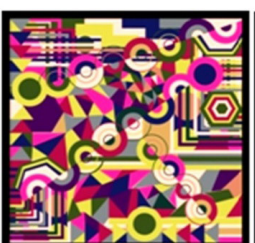

Ön Tasarm 6

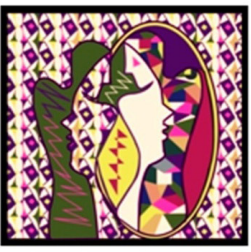

Ön Tasarmm 10

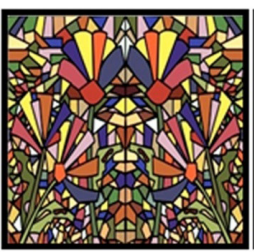

Ön Tasarm 3

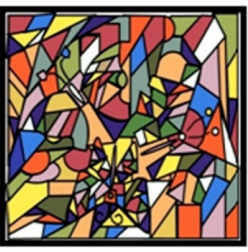

Ön Tasarm 4

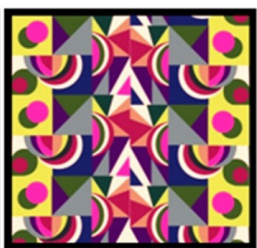

Ön Tasarm 7

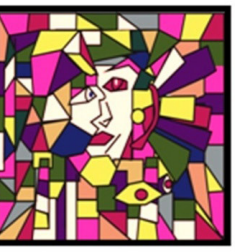

Ön Tasarmm 11

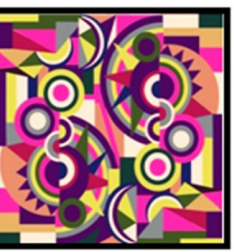

Ön Tasarm 8

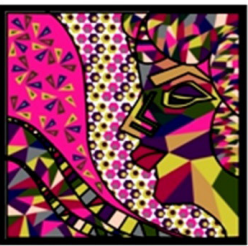

Ön Tasarm 12 
Fact finding: Team 2 derived inspiration from Pablo Picasso, famous painter and his Cubic designs. Studying Picasso's biography and designs, the team concluded about the subfunctions of the design F1 (Material or structure) as \%100 silk Satin; F2 (Print technique) as digital print; F3 (Design style) as Cubism; F4 (Motif form) as Stylized; F5 (Motif style) as geometric and ribbon motifs and F6 (Color) as

Project 3: Print fabric collection for women dress (Table 6)

\section{AW trend colors}

Idea finding: Team 2 decided to derive ideas from neighborhood and use scenes from daily life.

Concept generating: Team 2 used 2D sketching techniques, namely hand sketched all the scenes in mind. Then they transferred all the sketches (around 30 sketches) to CAD software and colored.

Table 6 Concept generating phases for Project 3

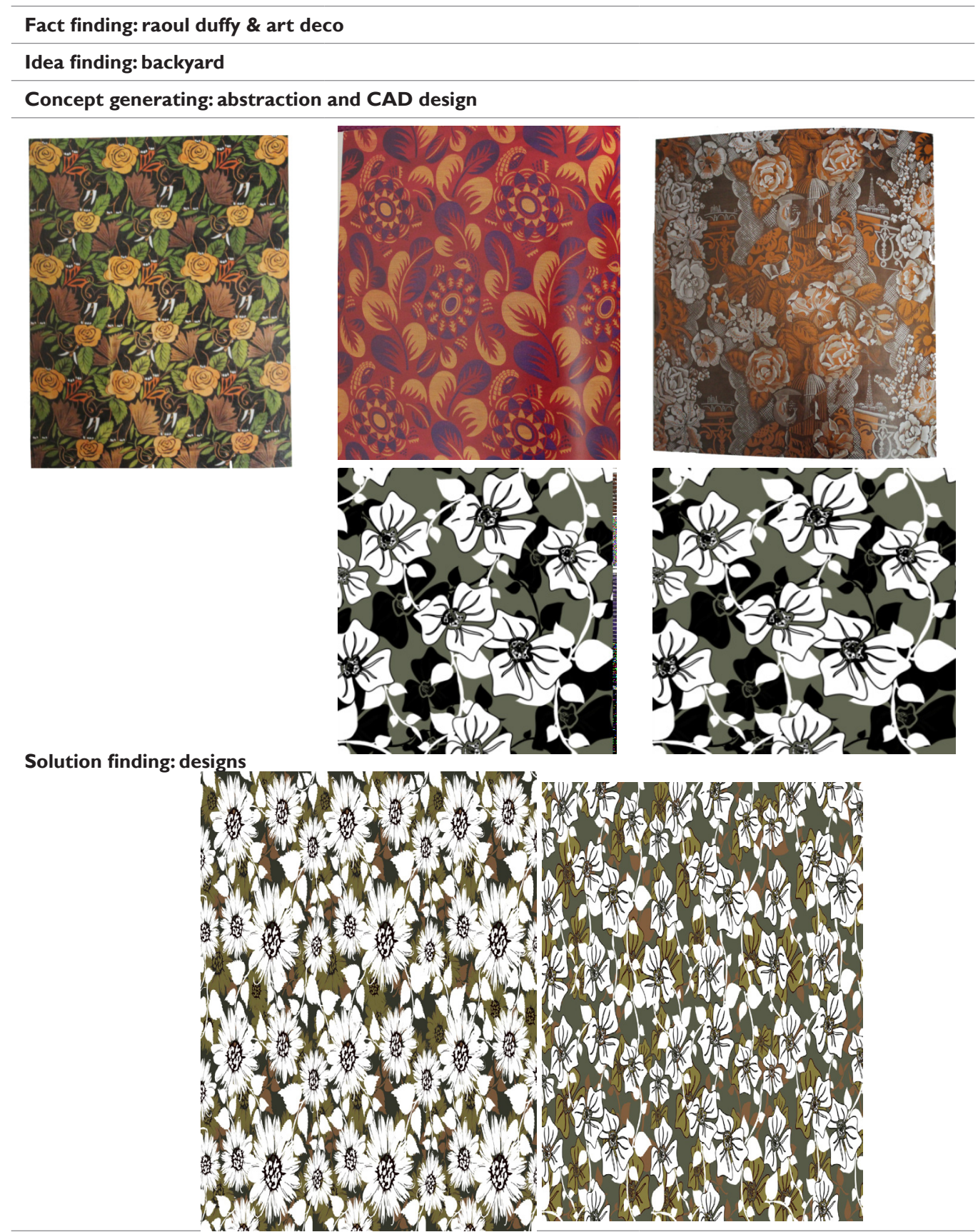

Fact finding: Team 3 derived inspiration from Raoul Duffy, famous designer and his Art Deco designs. Studying Duffy's biography and designs, the team concluded about the subfunctions of the design F1 (Material or structure) as \%100 silk Satin; F2 (Print technique) as digital print; F3 (Design style) as Art Deco; F4 (Motif form) as Stylized F5 (Motif style)as Vegetal and F6 (Color) as 2017AW trend colors
Idea finding: Team 3 decided to derive ideas from backyard and use photos taken from the garden.

Concept generating: Team 3 generated their concepts by abstracting Duffy's previous designs. Then they transferred all the sketches (around 30 sketches) to CAD software and colored. 


\section{Project 3: Print fabric collection for women dress (Ta- ble 6)}

Goldschmidt describes the use of various methods for representing concepts, which include written and oral representations, threedimensional models, diagrams, ad-hoc graphic utterances, and sketches Goldschmidt. ${ }^{18} \mathrm{Oxman}^{34}$ explain these as visual and mental transactions between an individual and that which he or she is trying to represent. Fashion conceptualists have been more concerned with tackling philosophical questions than considering their implications for investment in new machinery and workforce-training should the garment go into large-scale production Carr \& Pomeroy; ${ }^{30}$ McDowell; ${ }^{26}$ Benaim; ${ }^{35}$ Braddock \& O Mahony. ${ }^{36}$

Evaluation: As the last step of Conceptual Design process of engineering design, researchers have to evaluate variants against technical and financial criteria and have to decide for the optimal solution combinations at the end of the process. In engineering design problems the necessity of combining working principles into working structures may occur, but since non-functional textile design is not a complex medium, teams decided to bypass this step finding it unnecessary. When selecting suitable combinations for the optimal manufacturing conditions and features of the product is determined, teams ended up evaluating all the possible combo of solution. Successful designers are aware that the combinatory play of combining basic elements of yam, color, shape, form, style, theme, and motif is not enough.

Textile and clothing concepts, as visual responses to information and ideas collected at the research stage, represent early attempts at solving problems. The visual concepts of a fashion or textile designer can be represented in a painting, sketch, story board, or fabric sample Carr \& Pomeroy ${ }^{30}$ Essential to the successful development of new products is the ability of designers to externalize concepts Verstijnen et al. ${ }^{37}$ For the evaluation and adoption (solution finding) phase a textile designer may make some calculations, 3 dimensional models, samples or depend only on his or her experience and insight. This stage is called firming up into principle solution variants stage. Then as the last step of Conceptual Design process of engineering design, researchers have to evaluate variants against technical and economic criteria and choose the optimal solution combinations at the end of the process.

At the last step of this research the teams proposed their collections to the market. The first team composed a collection of 3 fabric styles and their color variants; the second team composed a collection of 12 scarves and the third team composed of 2 fabrics and their color variants. ${ }^{38-42}$

\section{Conclusion}

It is not wrong to say that a designer starts by thinking about the concept and context of the problem first, then by proposing a solution to satisfy the contend of the problem, he transforms initial stage into a final design. As a specific type of designer, textile designers have to blend technology-chemistry, fiber physics, knit, weave and spinand aesthetics-color, composition, texture and form-to create textiles that meet customer requirements. This is a complex process. These factors alone justify textile design being allocated its own professional category. This paper, using Conceptual Design principles, explains and maps the design process in each step. Just in three phases of concept design problem definition and preparation (fact finding) were realized through intense research and investigation and thinking up ideas (idea finding) stage was done through functionalizing the design problems dividing into many subfunctions.

This research concludes that design solutions put forth by the designer during the conceptual stage are the offspring of many design decisions done before. Three completely different textile collections were achieved using the same algorithm respond to the fact that Conceptual Design Method can be used as a creative analysis process in textile design problems providing a high level of creativity. Maybe the methodology proposed in this paper does not provide the fastest route to solving design problems. However, it does provide a technique for concept generating and solution finding.

\section{Acknowledgments}

I thank all of my three participant students for sharing their design experiences and design projects with me to support the implementation of the study. I strongly hope that this valuable feedback and comments on the final results could be useful for designers.

\section{Conflict of interest}

There is no conflict of interest.

\section{References}

1. Assoreira Almendra R. Decision Making in the Conceptual Phase Of Design Processes: A Descriptive Study Contributing For The Strategic Adequacy And Overall Quality Of Design Outcomes. PhD Thesis, Faculdade de Arquitectura from Lisboa University of Technology, Lisbon, Portugal; 2010. p. 391.

2. Love T. Counter-intuitive Design Thinking: Implications for Design Education, Research and Practice. Cumulus 38 South Conferences, Swinburne University, Melbourne, Victoria, Australia; 2009. p. 1-12.

3. Christiaans H, Restrepo J. Problem structuring and information access in design. 2004.

4. Pahl G, Beitz W. Engineering Design. London: The Design Council, 1984. p. 1-18.

5. Roozenburg N, Eekels J. Product Design: Fundamentals and Methods. Chichester, New York: John Wiley \& Sons; 1995. p. 408

6. Studd R. The Textile Design Process. The Design J. 2002;5(1):35-49.

7. Moxey J. A creative methodology for idea generation in printed textile design. J Text lnst. 1998;89(3):35-43.

8. Pahl G, Beitz W. Engineering Design: A Systematic Approach. Berlin Springer; 2007. p. 617.

9. Kannengiesser U, Gero JS. A comparison between Pahl and Beitz'systematic approach and the design behavior of mechanical engineering students. 2015. p. 1-26.

10. Osborn A. Applied imagination: Principles and procedures of creative problem solving. 3rd ed. New York: Charles Scribner's Sons; 1963. p. 417.

11. Wodehouse AJ, Ion WJ. Information use in conceptual design: Existing taxonomies and new approaches. International J Design. 2010;4(3):53-65.

12. Newell A, Shaw JC. The process of creative thinking. In: Newell A, Simon HA, editors. Human Problem Solving, Prentice Hall, Englewood Cliffs. New Jersey, USA; 1972. p. 1-86.

13. Dt ogilvie. Creative action as a dynamic strategy: using imagination to improve strategic solutions in unstable environments. $J$ Business Research. 1998;41(1):49-56. 
14. Goldschmidt G. The dialectics of sketching. Creativity Research J. 1991;4(2):123-143.

15. Dorst K, Cross N. Creativity in the design process: co-evolution of problem-solution. Design Studies. 2001;22(5):425-437.

16. Colchester C. Hi-Tech Styles. Crafts. 1995;132:20-23.

17. Cooke C. An Introduction to Design (T2O4 Block 1). Milton Keynes, Bucks: The Open University Press; 1995.

18. Goldschmidt G. Capturing Indeterminism: Representation in the design problem space. Design Studies. 1997;18(4):441-455.

19. Bruce M, Cooke B. Textile design-the right approach. Text. Horizons. 1998.

20. Tucker A. Dries Van Noten: Shape, Print and Fabric. London: Thames \& Hudson; 1999. p. 2.

21. Giampà F, Muzzupappa M, Rizzuti S. Design by Function: A Methodology to Support Designer Creativity. International Design Conference. Dubrovnik, Croatia, 2004. p. 225-232.

22. Mumford MD, Gustafson SB. Creativity Syndrome: Integration, Application and Innovation. Psychol Bull. 1988;103(1):27-43.

23. Perkins DN. The Possibility of Invention. In: Sternberg RJ, editor. The Nature of Creativity. 1988.

24. Joyce C. Textile Design: The Complete Guide to Printed Textiles for Apparel and Home Furnishing. Watson-Guptill Publications, New York, USA; 1993.

25. Roy Robin. Case studies of creativity in innovative product development. Design Studies. 1993;14(4):423-443.

26. McDowell C. Galliano, Phoenix, London; 1998.

27. Conran T. Printed Textile Design. The Studio, London, UK; 1957.

28. Frings GS. Fashion: From Concept to Consumer. NJ: Prentice-Hall, Englewood Cliffs; 1991.

29. Bruce M, Cooper R. Marketing and Design Management. London: International Thomson Business Press; 1997. p. 245
30. Carr H, Pomeroy J. Fashion Design and Product Development. UK: Blackwell Scientific Publications Oxford; 1992. p. 188.

31. McRobbie A. British Fashion Design: Rag Trade or Image Industry. Fashion theory. 1998;3(1):135-137.

32. Cross N. Engineering design methods, strategies for product design. Chichester: John Wiley \& Sons; 1994. p. 230.

33. Faure C. Beyond Brainstorming: Effects of Different Group Procedures on Selection of Ideas and Satisfaction with the Process. J Creative Behavior. 2004;38(1):13-34.

34. Oxman R. Design by Re-representation: A model of visual reasoning in design. Design Studies. 1997;18(4):329-347.

35. Benaim L. Issey Miyake. Antiquarische Fundgrube e.U, Austria; 1997.

36. Braddock SE, O Mahony M. Techno Textiles: Revolutionary Fabrics for Fashion and Design. Textile. 1998;4(3):386-388.

37. Verstijnen IM, Hennessey JM, van Leeuwen C, et al. Sketching and Creative Discovery. Design Studies. 1998;19(4):519-546.

38. Cross N. Expertise in design: An overview. Design Studies. 2004;25(5):427-441.

39. Dorst K. The problem of design problems. In: N Cross, E Edmonds, editors. Expertise in design. Creativity and Cognition Studio Press, Sydney, Australia; 2003. p. 1-13.

40. Hummels C, Frens J. Designing for the unknown: A design process for the future generation of highly interactive systems and products. Paper presented at the 10th International Conference Engineering and Product Design Education, Barcelona, Spain; 2008. p. 204-209.

41. Hummels C, Frens J. The reflective transformative design process. Proceedings of the 27th International Conference on Human Factors in Computing Systems. ACM, New York, USA; 2009. p. 2655-2658.

42. Weisberg RW. Creativity: Genius and Other Myths. Cognitive Psychology. 1986;1(1):74-75. 